\title{
Assessment of Displacement Contours during Individual Canine Retraction with the Application of Finite Element Method
}

\author{
MayankT ${ }^{1}$,Raghunath $\mathrm{N}^{2}$ \\ ${ }^{I}$ Post Graduate,Department Of Orthodontics, JSS Dental College \&Hospital, Mysuru, India \\ ${ }^{2}$ Professor \&Head,Department Of Orthodontics, JSS Dental College \&Hospital, Mysuru, India
}

\begin{abstract}
Objectives: To assess the displacement contours in $X, Y$ and $Z$ directions during individual canine retraction with finite element application and to comparethese displacements contours to the clinically occurring movements that cannot be visualized precisely in a clinical framework.

Materials and Methods: A three dimensional finite element model of the maxillary canine teeth along with its surrounding periodontal structure (teeth, PDL and bone) were created in order to simulate the movements with 150 grams of force for individual canine retraction.

Results:Force of 150 grams when applied for individual canine retraction showed displacement contours of $0.047 \mathrm{~mm}, 0.199 \mathrm{~mm}$ and $0.088 \mathrm{~mm}$ in $X, Y$ and $Z$ directions respectively.

Conclusion: Individual canine retraction with 150 grams of force moved the canine palatally inside during displacement in $X$ direction, distal displacement of the canine took place in $Y$ direction and extrusion of the anterior teeth happened with displacement in $Z$ direction.
\end{abstract}

Keywords: Displacement contours, Finite element method,Individual canine retraction, Orthodontics.

\section{Introduction}

Finite element method (FEM) with its highly specific technique and ease of computer application has been used in the field of orthodontics and other fields of dentistry from time to time. For many years it has been employed in the field of engineering for solving large amounts of equations and to calculate problems related to strain and stress among others. Ability of the finite element application to mimic the heterogeneity of the tooth along with its surrounding structures upon which loads from different direction and of varying magnitude when applied, makes it a unique toolfor performing complexequations [1].

Finite element method along with acquiring qualitative and quantitative results allows the application of different force systems and its distribution among the periodontal structures such as the tooth, periodontal ligament and alveolar bone [2]. Finite element technique has established itself in dental field involving simulation of tooth movement and evaluating mechanics in orthodontics. Finite element analysis (FEA) is a numerical analysis which permits the identification of displacement and stresses by entangling discretization (hypothetical subdivision of the structure in study) ofits continuum in a large number of elements [3].

Previous studies by finite element technique have concentrated on many variables such as relationship of moment to force ratios, loss of anchorage, efficiency of orthodontic appliances, comparing force magnitudes, center of rotation along with rate of tooth movement. Canine retraction is among the most common tooth movements in the field of orthodontics after the extraction of first premolars. It is important to understand the significance of biomechanical reaction of the teeth to the orthodontic loads in order to correlate it to the actual histological and morphological events during orthodontic tooth movement [4].

In order to achieve bodily movement of the canine during an individual canine retraction, application of optimum orthodontic force is of greatimportance since it is assumed that the rate at which the tooth movement takes place is force dependent. As the rate of tooth movement is sensitive to force magnitude, forces in the optimal range has to be applied so as to obtain a uniform movement of teeth into the extraction space without compromising the anchorage or in other words moving the teeth intended to be moved without moving the unitunder anchorage [5]. For achieving an optimum rate of canine retraction there prevails an optimum level of force [6]. To move the canine distally and bodily a force level in the range of 150 to 200 grams are needed to be applied, the force range exceeding beyond this level may decrease the rate of tooth movement and may approach a level of zero movement [7].

Finite element method (FEM) with its application was aimed to investigate the displacement contours in terms of retraction rate while bodily movement of the canine takes place with application of optimum orthodontic force. 


\section{Material And Methods}

A case of dental bimaxillary protrusion involving extraction of all first premolars undergoing fixed orthodontic mechanotherapy at J.S.S Dental College and Hospital, Mysuru (India) was selected for acquiring treatment records for the purpose of preparing finite element models and simulating the models with 150 grams of force. Patient undergoing fixed orthodontic therapy was planned for individual canine retraction using Niti coil springs of $6 \mathrm{~mm}$ length that applied a force level of 150 grams for the canine tooth to be retracted. After the placement of Niti coil spring clinical photographs and CT scan of the patient under study were taken for the purpose of replicating the teeth, periodontal ligament (PDL) and the bone for finite element modelling (figure 1 $\& 2)$.

Fig 1: Intraoral Photographs of Pre and Post Individual Canine Retraction with 150 Grams of Force
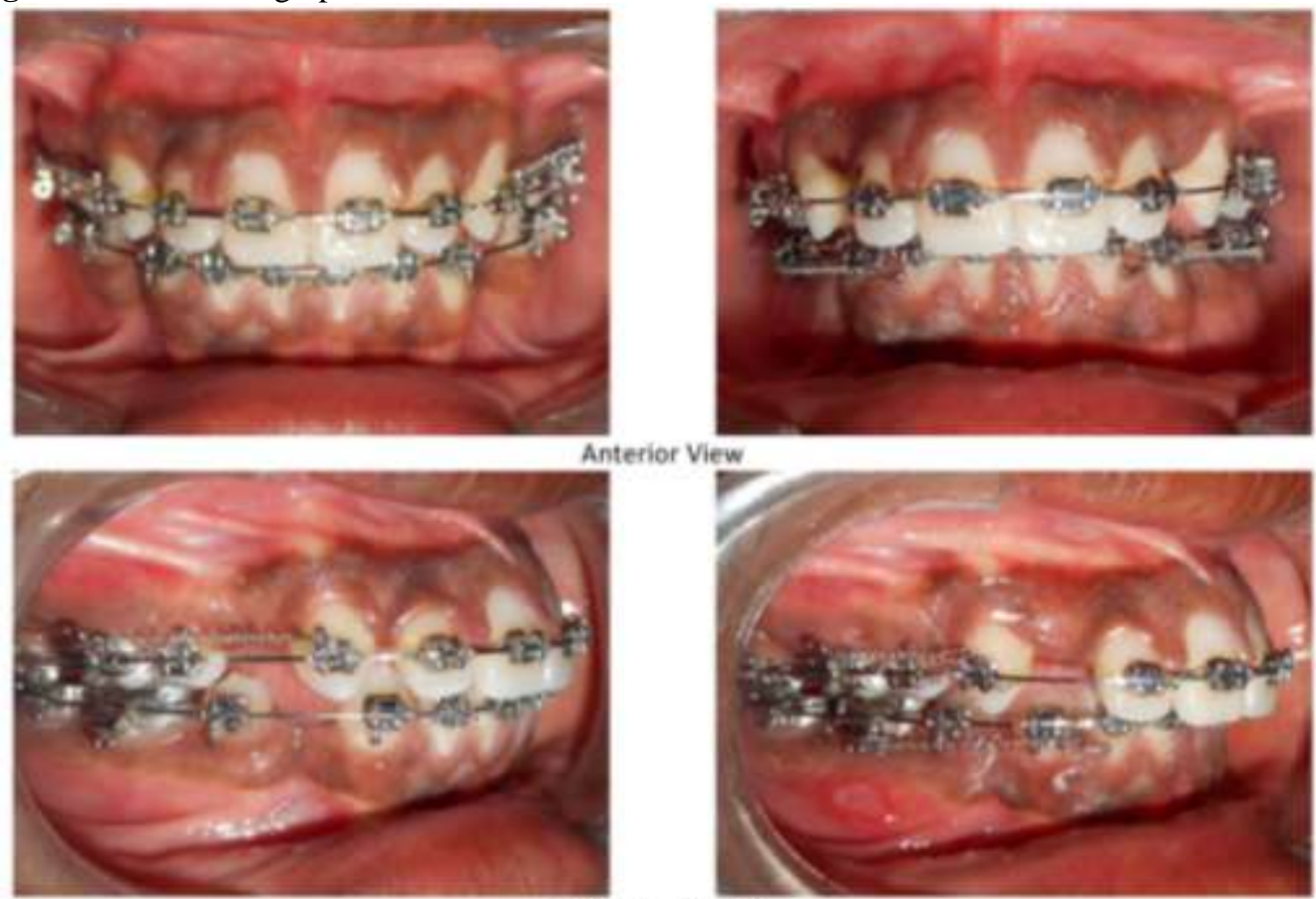

Right Lateral View

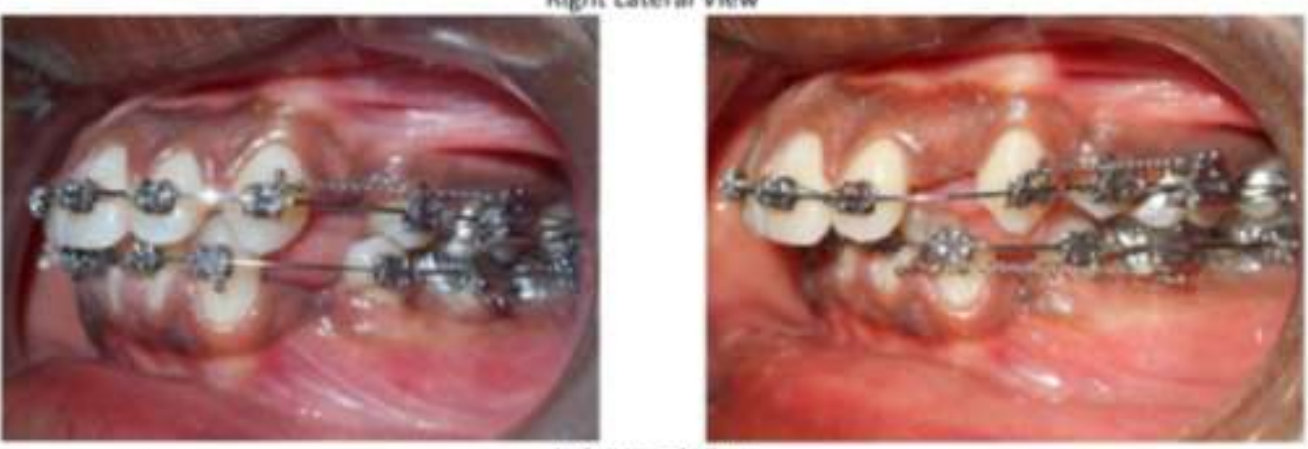

Left Lateral View

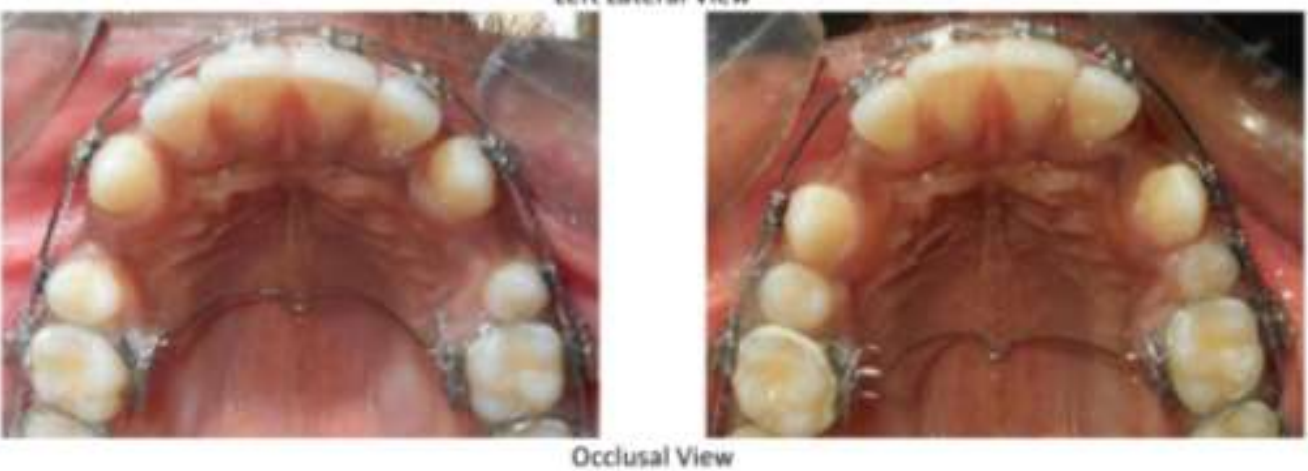


Fig 2: Ct Scans of Pre and Post Individual Canine Retraction with 150 Grams of Force
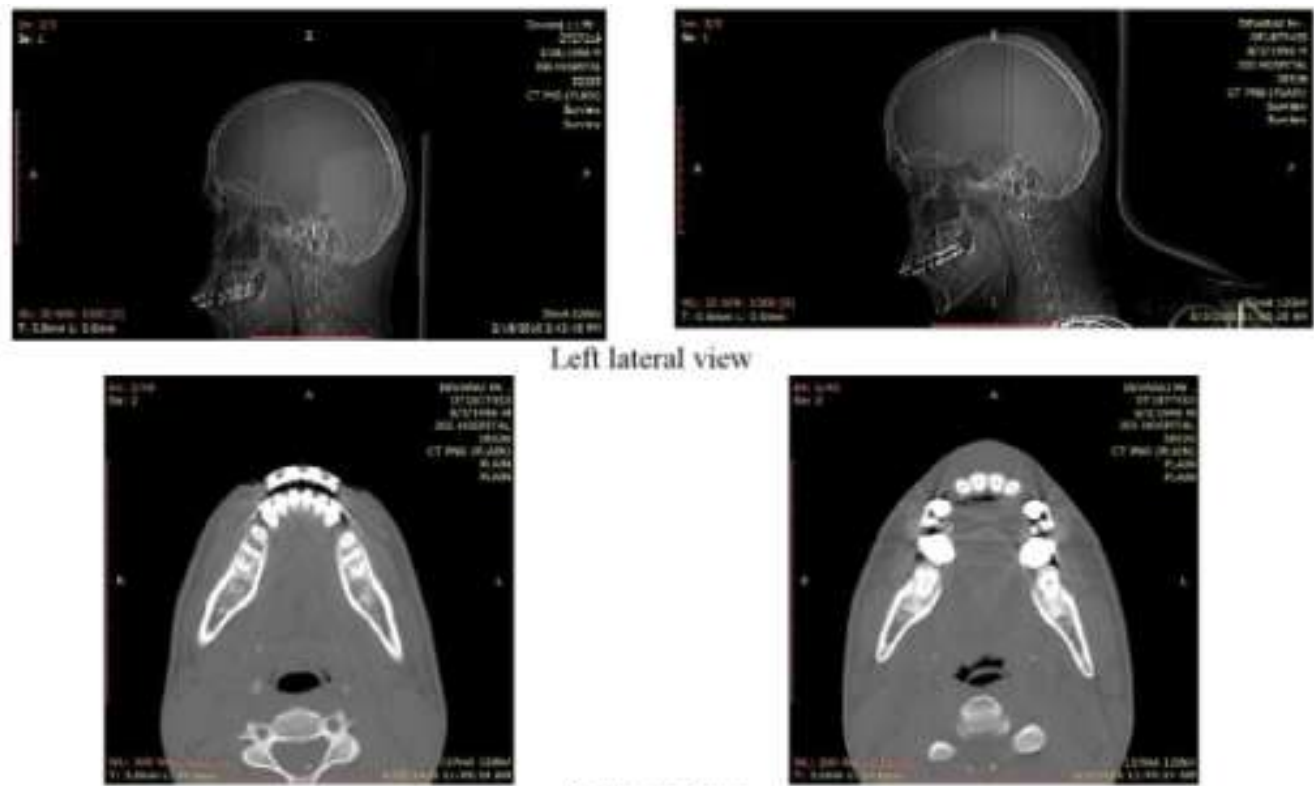

Left lateral view

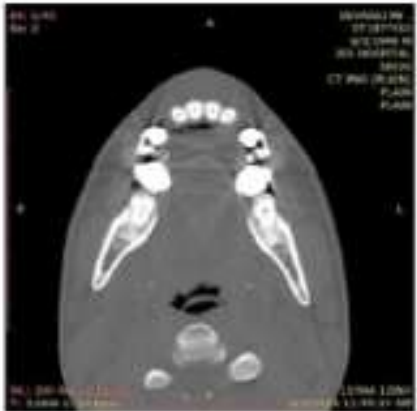

Occlusal view

Workstation computer with following configuration: Intel core 2 duo with $2.1 \mathrm{GHz}, 2 \mathrm{~GB}$ of RAM, 2GB Graphics card, 320GB hard Disc,17" Monitor. Spiral C.T Scan Machine. An X-force/SH spiral C.T scan machine was used for taking the CT scan images of the cranium from which maxilla was extracted for the current study.Software's used: Mimics 8.11:- Materialize Interactive Medical Image Control System (MIMICS) is amedical modeling software used for the visualization and segmentation of CT/MRI images.

ANSYS 12.1: Analysis System Software- This software is used for carrying out Finite element Analysis of structures and Fluids for various applications like Automotive, Civil, Manufacturing, Aerospace and Biomedical fields.

Rapid FORM2004:Software Used To convert cloud data pointsto surfaces, the converted surfacesare stored in IGES Format.Hypermesh 13.0: Software used for converting geometric model into finite element model.Altair Hyper Works is the engineering framework for product design for maximizing product performance, automating design processes, and improving profitability within an open and flexible environment. Geometric models of the maxilla including the teeth, PDL were then imported into the meshing software "hyper mesh". In hyper mesh the individual parts like soft bone, hard bone, teeth, PDL, brackets, wire, mechanism device are then discretized (meshing) and assembled (figure 3 and 4). The material properties, loads and boundary conditions was assigned to the FEM-model (table 1).

Table 1: Material properties

\begin{tabular}{|l|c|c|}
\hline \multicolumn{1}{|c|}{ Materials } & Young's Modulus $\left(\mathbf{N} / \mathbf{m m}^{2}\right)$ & Poisson's Ratio \\
\hline Teeth & $2.60 \mathrm{E}+04$ & 0.30 \\
\hline PDL & $6.80 \mathrm{E}-01$ & 0.49 \\
\hline Bone & $1.40 \mathrm{E}+04$ & 0.30 \\
\hline Bracket & $2.14 \mathrm{E}+05$ & 0.30 \\
\hline Steel & $2.00 \mathrm{E}+05$ & 0.31 \\
\hline SS303 & $1.93 \mathrm{E} 5$ & 0.3 \\
\hline
\end{tabular}


Fig 3: Geometric Model for Individual Canine Retraction with 150 Grams of Force
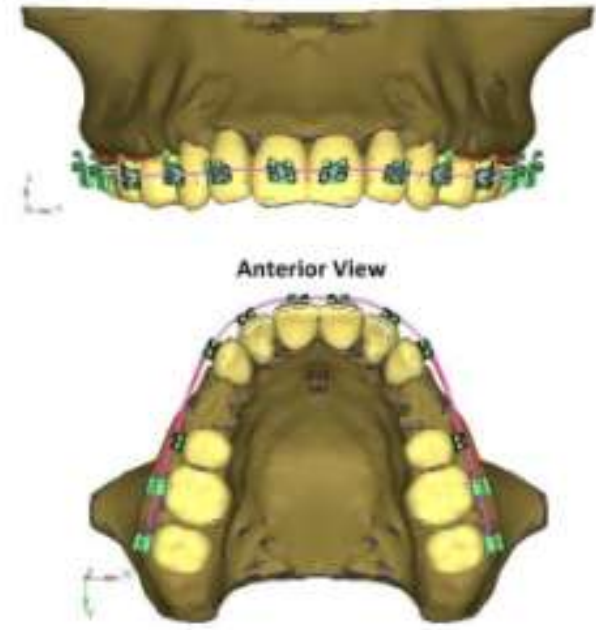

Occlusal View

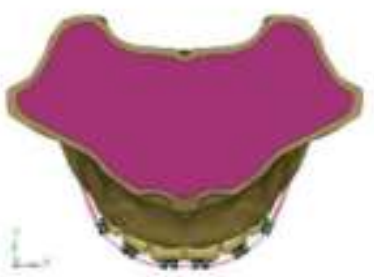

Top View

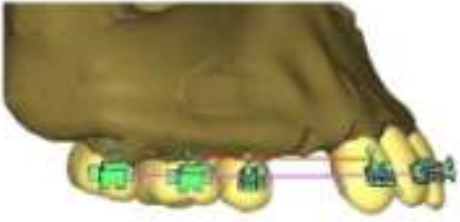

Lateral View

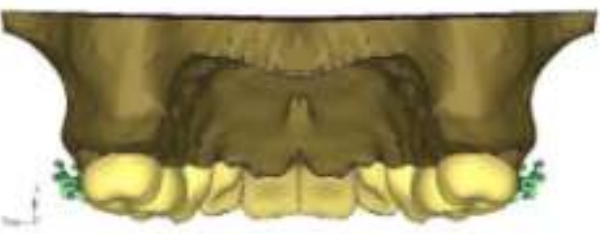

Rear View

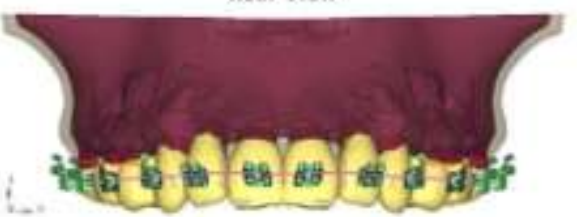

Outer Cortical Bone and Inner Cancellous Bone

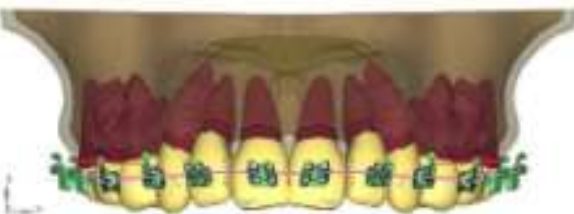

Transparent Vlew showing roots of Teeth and PDL around it.

Fig 4: Finite Element Model for Individual Canine Retraction with 150 Grams of Force

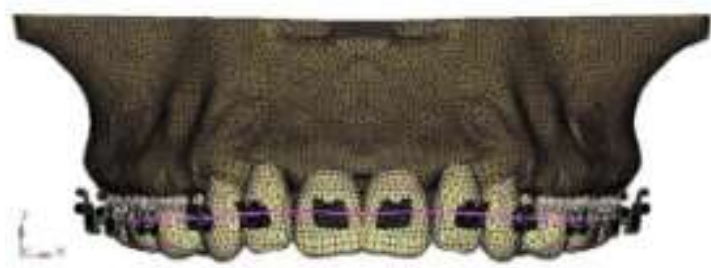

Anterior view

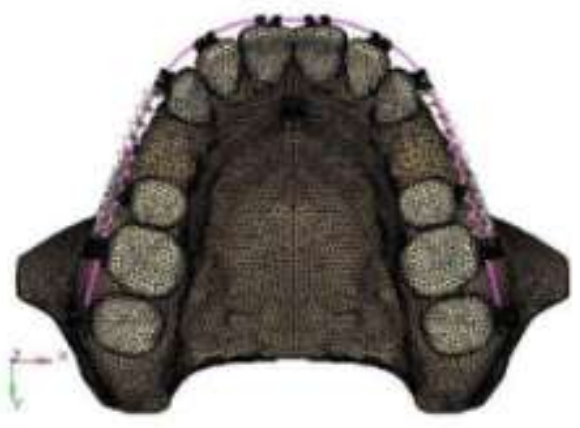

Occlusal view

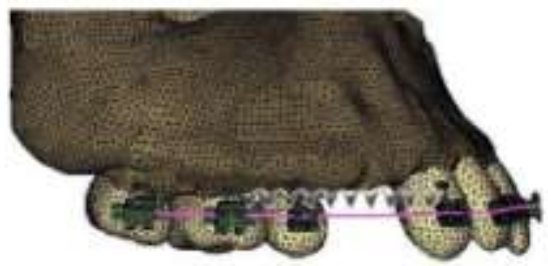

Lateral view

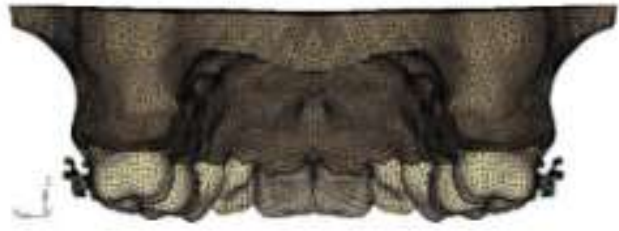

Rear View 


\section{Results}

According to the results of the study with application of 150 grams of force we obtained the displacement contours of the canine in $\mathrm{X}, \mathrm{Y}$ and $\mathrm{Z}$ directions with its related outcomes in context to orthodontic tooth movement (figure 4, 5 and table 2)

Fig 5: Applied Loads and Boundary Conditions with 150 Grams Of force along with Displacement Contours seen in Maxilla

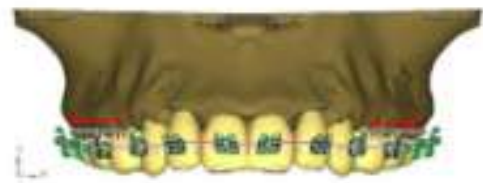

Anterie View

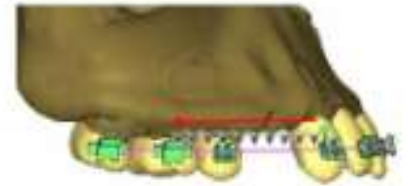

Laseral View

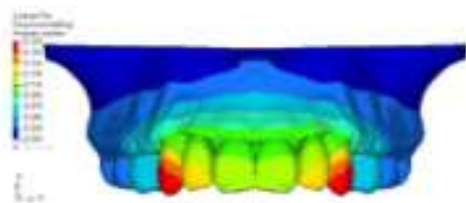

Anterior View

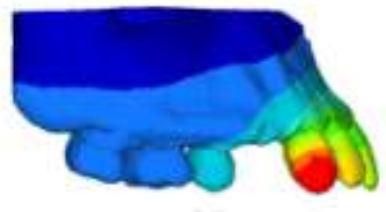

Iteral View

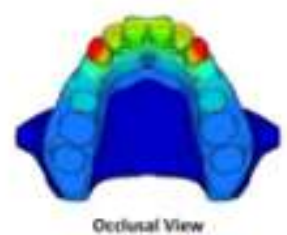

Fig 6: Displacements Contours In X, Y and Z Directions with 150 Grams of Force

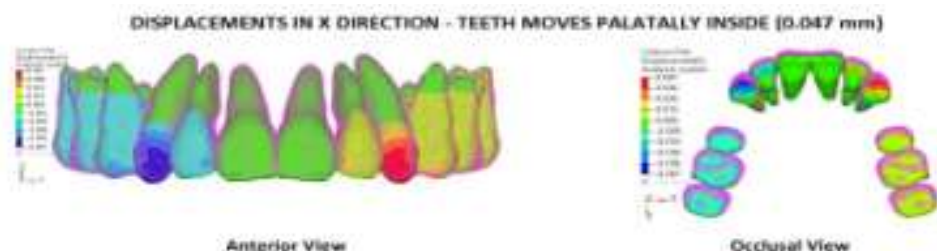

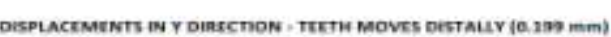

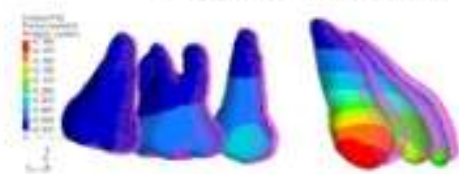

Lateist view

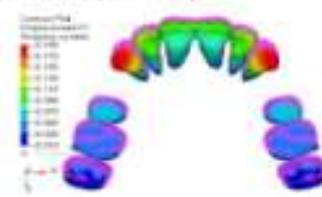

Octiveal View

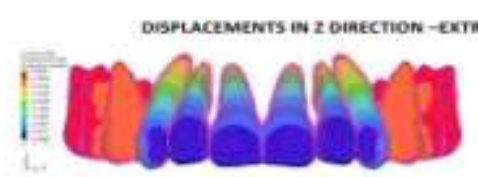

Anterior Vlew

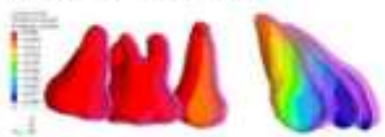

Gateral view

Table 2: Displacement Contours in Maxilla in $\mathrm{X}, \mathrm{Y}$ and $\mathrm{Z}$ directions in Individual Method of Canine Retraction with 150 Grams of Force.

\begin{tabular}{|l|c|c|}
\hline \multicolumn{1}{|c|}{ DIRECTION } & DISPLACEMENT (mm) & TYPE OF MOVEMENT \\
\hline X DIRECTION & $0.047 \mathrm{~mm}$ & PALATALLY INSIDE \\
\hline Y DIRECTION & $0.199 \mathrm{~mm}$ & DISTALLY \\
\hline Z DIRECTION & $0.088 \mathrm{~mm}$ & EXTRUSION OF ANTERIORS \\
\hline
\end{tabular}


The displacement contours in $\mathrm{X}$ direction with 150 grams of force was seen to be $0.047 \mathrm{~mm}$ and the canine undergoing the retraction process was observed to have moved inside in a palatal direction. The displacement contours in $\mathrm{Y}$ direction with 150 grams of force was seen to be $0.199 \mathrm{~mm}$ and the canine undergoing retraction process was observed to have moved in a distal direction. The displacement contours in $\mathrm{Z}$ direction with 150 grams of force was seen to be $0.088 \mathrm{~mm}$ and the canine under the retraction process was seen to have undergone extrusion along with the whole anterior segment involving central and lateral incisor of the same side along with the central and lateral incisors and canine of the contralateral side.

\section{Discussion}

Finite element analysis for calculating and assuming the behavior of dental and its related structures started in the seventies with 2 dimensional (2D) and 3 dimensional (3D) modelling of the structures involved. In the field of orthodontics finite element applications have been seen to be applied to orthodontic appliance functioning and its effects in relation to tooth movement and its related soft and hard tissues [8].Patterns of tooth displacements have been studied in the past with application of finite element method for detecting the patterns of tooth displacements with respect to upper incisor tooth in relation to varying alveolar bone heights and were observed to have an inverse relation to the root length and bone height of the alveolus supporting the bone [9].Speaking in practical terms the teeth, periodontal ligament (PDL) and bone are heterogeneous and anisotropic, as data for these structures are not available. These structures are assumed to be linear homogenous and isotropic. Most of the finite element analysis are carried out keeping in mind the assumption and not an accurate reproduction of the real or clinical situation, hence finite element analysis (FEA) can only help us to understand the initial displacements or behavior of any system.

In a study by Kazuo Tanne et al [10], for calculating the correlation between moment to force ratio and centers of rotation by finite element method (FEM), obtained a moment to force ratio of -8.39 for a translatory or a bodily movement however the displacements of the tooth had taken place only in $\mathrm{Y}-\mathrm{Z}$ plane and there were negligible displacements in X-Y plane, they found that the mesiodistal displacement were negligible which led to a uniplanar interpretation of the data,hence they thrived to achieve results those were obtained in more than one plane of space by application of 3 dimensional method. They also mentioned that some studies for describing the center of rotation used only the horizontal displacement and did not pay much importance to the displacements in vertical planes of space, hence with the advancement of the finite element technique in our study displacements or movements in vertical plane of space were also predicted.

In a study conducted by Kojima and Fukui [11] for simulation of canine retraction with the application of $2 \mathrm{~N}$ (200 grams) of force, the frictional force applied to the canine was $1.47 \mathrm{~N}$ out of which the net force transmitted to the canine was $0.53 \mathrm{~N}$ which was about $27 \%$ of the force of $2 \mathrm{~N}$ applied to the bracket and the same frictional force of $1.47 \mathrm{~N}$ was applied to the wire in the distal direction and the same amount of force 0.53 $\mathrm{N}$ were transmitted to the wire in the mesial direction. Movements such as loss of anchorage, bodily movement of the incisors, premolar and molar along with tipping of the second molar was observed. Incisor extrusion of about $1 \mathrm{~mm}$ took place because of the transfer of moment by the canine to the wire with the application of reaction force. This finding alone was in accordance with the results of our study however the amount of extrusion was $0.088 \mathrm{~mm}$ in our study.

According to a study conducted by Junjie et al [12] a force vector of $1.5 \mathrm{~N}$ (150 grams) was applied bilaterally to move the canine in a distal direction. 3 models were created for the study, model 1 for nonsurgical canine retraction which can be taken as a reference to our canine study model, model 2 with canine retraction using periodontal distraction and model 3 for dentoalveolar distraction. The displacement of canine was seen to be of about $1.8 \mathrm{~mm}$ in the model 1 group (nonsurgical) and was highly concentrated at the distal areas of the crown which can be correlated with the findings of our study in which a distal displacement contour was noted in $\mathrm{Y}$ axis but the movement of $0.199 \mathrm{~mm}$ in our study compared to $1.8 \mathrm{~mm}$ in the study by Junjie et al ${ }^{11}$ did not correlate with the results of our study. This study by Junjie et al [12] was conducted in relation to rapid canine retraction but as the retraction forces were of $150 \mathrm{~N}$ which was interms of force levels to our study and was a nonsurgical procedure, an attempt was made to correlate it with our study.

In a study conducted by DuanQiang ZHANG et al [13] for en masse retraction of six anterior teeth with 150 grams of force in a set of two models, in case 1 for routine canine retraction from an anterior hook of $2 \mathrm{~mm}$ and the molar tube and in case 2 canine retraction from an anterior hook of $4 \mathrm{~mm}$ and an implant which was placed $10 \mathrm{~mm}$ towards the gingiva from the site of the molar tube were used. In relation to finite element simulations for bodily canine movement in our study with 150 grams of force it was observed that the displacement contours of all the anterior teeth had taken place which was in similarities to the displacements in en masse retraction with 150 grams of force, hence it could be correlated with the fact that in one way or the other forces for bodily movement has an indirect effect on the structures surrounding the teeth that is intended to be moved or displaced. With these findings an effort was made to compare and correlate the displacements of bodily canine retraction to that of en masse canine retraction as the force levels used were same and the 
surrounding structures were also affected in our study. In this context, by the findings of DuanQiang ZHANG et al [13]in X direction the lateral incisor showed lingual displacements with respect to crown and root whereas central incisor and canine showed labial and lingual displacement respectively, these finding were in contrast to our study. However in $\mathrm{Z}$ direction, in our study the canine along with its surrounding teeth displayed extrusion which can be correlated to the findings of DuanQiang ZHANG et al [13]that also depicted extrusion of canine only and not lateral incisor which showed only intrusion and central incisor showed only minor displacement.

At last, it can be understood that studies related to the field of finite element cannot provide comprehensive clinical results and can only consider initial continuous displacements taking place in the real situation along with other parameters of stress analysis. Despite its limitations, finite element method proves to be a precision method in plotting and correlating the displacement contours with orthodontic force applications.

\section{Conclusion}

1. Displacement contours give an idea of the actual initial displacement and behavior of the teeth which could be of use for the clinicians in anticipating movement with different magnitudes of forces.

2. Movements taking place in the distal $(\mathrm{Y})$ direction and palatally $(\mathrm{X})$ inward directionby finite element method may recommend an orthodontic procedure for aligning a highly and buccally placed canine in order to retract and align the canine into the extraction space

3. With individual canine retraction by application of 150 grams of force, a distal and palatal movementswere expected, but with bodily movement of canine there was also extrusion of the anterior teeth ( $\mathrm{Z}$ direction) other than the canine, which is usually seen during en masse retraction in a clinical situation. Hence with this finding a need for levelling the curve of spee may arise in a clinical situation after a bodily canine retraction has taken place.

4. Finite element analysis are carried out keeping in mind the assumption and not an accurate reproduction of the real or clinical situation hence finite element analysis (FEA) can only help us to understand the initial displacements or behavior of any system.

\section{References}

[1]. DJ Rudolph, MG Willes and GT Sameshima, A finite element model of apicalforce distribution from orthodontic tooth movement, Angle Orthod, 71,2001,127-131.

[2]. MI Puente, L Galban and JM Cobo, Initial stress differences between tipping and torque movements, A three-dimensional finite element analysis, European Journal of Orthodontics, 18,1996,329-339.

[3]. A Geramy, Initial stress produced in the periodontal membrane by orthodontic loads in the presence of varying loss of alveolar bone: a three dimensional finite element analysis. European Journal of Orthodontics,24,2002,21-33.

[4]. Y Jing, XL Han, BH Cheng and B Ding, Three-dimensional FEM analysis of stress distribution in dynamic maxillary canine movement, Chin Sci Bull,58,2013,2454-2459.

[5]. RS Quinn and DK Yoshikawa, A reassessment of force magnitude in orthodontics, Am. J. Orthod, 88,1985,252-260.

[6]. E Storey and R Smith, Force in orthodontics and its relation to tooth movement, Aust. J. Dent 56,1952,291-304.

[7]. GF Andreasen and D Zwanziger, A clinical evaluation of differential force concept as applied to the edgewise bracket, Am J. Orthod, 78,1980,25-40.

[8]. J Cobo, A Sicilia, J Arguelles, D Suarez and M Vijande, Initial stress induced in periodontal tissue with diverse degrees of bone loss by an orthodontic force: Tridimensional analysis by means of finite element method, American JOrthodandDentofacOrthop,104,1993,448-54.

[9]. K Taane, T Nagataki, Y Inoue,MSakuda, CJ Burstone and HA Koenig, Patterns of initial tooth displacements associated with various root length and alveolar bone heigths, Am J OrthodDentofacOrthop,11,1991,66-71.

[10]. K Tanne, HA Koenig and CJ Burstone, Moment to force ratios and center of rotation, Am J OrthodDentofacOrthop, 94, 1988, 426431.

[11]. Y Kojima and H. Fukui, Numerical simulation of canine retraction by sliding mechanics, Am J OrthodDentofacOrthop, 127, 2005, 542-551.

[12]. XUE Junjie, YE Niansong, YANG Xin, WANG Sheng, WANG Jing, WANG Yan,LI Jingyu, MI Congbo and LAI Wenli, Finite element analysis of rapid canine retraction through reducing resistance and distraction, J Appl oral Sci,22(1),2014,52-60.

[13]. ZHANG DuanQiang, SU Jie Hua, XU Lin Yu and ZHONG Ping Ping, 3D finite element study of en masse retraction of maxillary anterior teeth in two typical force directions, The Chinese Journal of Dental Research, 11,2008,101-107. 